\title{
Perception towards Insulin Therapy and Factors Related to Insulin Refusal among Insulin Naive Type 2 Diabetes Mellitus Patients in Primary Care Clinics PKD Lipis
}

Noralina Zakaria ${ }^{1^{*}}$, Narasimman Baskaran² and Wan Lin Lim ${ }^{3}$

\begin{abstract}
Introduction: Insulin is one of the suggested treatments to prevent and reduce long-term diabetes complications. However, due to many factors such as socio-demographic factors, many Type 2 diabetes mellitus patients refuse this treatment. This study aimed to determine perception towards insulin among naive Type 2 diabetes mellitus patients, to calculate the prevalence of rejecting insulin therapy, and to find out factors related to the refusal.
\end{abstract}

Materials and methods: This cross-sectional study involved 188 insulin naive Type 2 diabetes mellitus patients attending five primary health clinics in Lipis district, Pahang from October to November 2017. A five-point Likert Scale was used to determine perception towards insulin therapy and the Chi-square test was used to assess the proportion of acceptance of the therapy. Simple and multiple logistic regressions were utilised to study the associated factor(s).

Results: Mean score of $60.5 \pm 8.2$ pointed towards a negative appraisal of insulin therapy. Embarrassment to inject in public $(69.1 \%)$ and concern of frequent hypoglycaemia $(52.7 \%)$ were the most common perception. Nearly half of the respondents (46.3\%) refused insulin therapy upon suggestion. After adjusting the variables using multiple logistic regressions, only gender (Adjusted $\mathrm{OR}=0.20,95 \% \mathrm{Cl}=0.10-0.40, p<0.001$ ), educational level (Adjusted $\mathrm{OR}=0.17,95 \% \mathrm{Cl}=0.06-0.50$, $\mathrm{p}=0.001$ ), age (Adjusted $\mathrm{OR}=1.04,95 \% \mathrm{Cl}=1.01-1.08, \mathrm{p}=0.012$ ) and glycated haemoglobin level (Adjusted OR=1.33, 95\% $\mathrm{Cl}=1.07-1.67, \mathrm{p}=0.013$ ) remained significant.

Conclusion: In conclusion, insulin refusal among insulin naive patients was common in Lipis with an overall negative perception towards therapy. By tailoring strategies according to the patient's factors such as gender, educational level, age, and glycated haemoglobin level, the insulin refusal rate might decrease in the future.

\section{ARTICLE HISTORY:}

Received: 30 August 2020

Accept: 3 May 2021

Published: 31 July 2021

\section{KEYWORDS:}

Insulin Refusal, Insulin Naive, Type 2 Diabetes Mellitus

\section{HOW TO CITE THIS ARTICLE:}

Noralina Zakaria, Narasimman Baskaran and Wan Lin Lim (2021). Perception towards Insulin Therapy and Factors Related to Insulin Refusal among Insulin Naive Type 2 Diabetes Mellitus Patients in Primary Care Clinics PKD Lipis. Journal of Pharmacy, 1(2), 70-78.

doi: 10.31436/jop.v1i2.52

\section{*Corresponding author:}

Email address: noralinazakaria1389@gmail.com

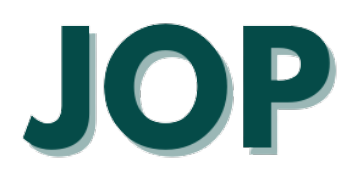

\section{Authors' Affiliation:}

\footnotetext{
${ }^{1}$ Perkhidmatan Klinik Bergerak (Bas) Lipis, Pejabat Kesihatan Daerah Lipis, 27200 Kuala Lipis, Pahang.

${ }^{2}$ Klinik Kesihatan Sungai Koyan, 27200 Lipis, Pahang.

${ }^{3}$ Klinik Kesihatan Benta, 27100 Jerantut, Pahang
} 


\section{Introduction}

Diabetes situation in Malaysia is worrying as the trend continues to increase by year. As reported by National Health and Morbidity Survey (NHMS) in 2011, the prevalence of diabetes in Malaysia showed an increment from $11.6 \%$ in 2006 to $15.6 \%$ in 2011 . By the year 2020 , the prevalence of diabetes among Malaysian adults will be expected to increase up to $21.6 \%$ (Ministry of Health, 2012). Meanwhile, in Pahang, the NHMS survey 2015 concluded that $14.8 \%$ (147676) of adults 18 years and above are diagnosed with diabetes (Ministry of Health, 2015).

Throughout the year of therapy, $\beta$ cell function in patients with diabetes will diminish, causing treating diabetes with oral glucose lowering-drugs (OGLDs) alone will be insufficient. Thus, insulin therapy is required for optimal control of glucose level. According to the 6th Edition of Malaysian CPG Management of Type 2 Diabetes Mellitus (T2DM), OGLDs remain the mainstay treatment of T2DM in combination with lifestyle intervention and appropriate dietary regimen. Insulin therapy can be initiated for all ages and at any stage of T2DM. The variety of treatment options and regimens available make it possible for better personalisation of the treatment to the patient (Ministry of Health, 2018).

Insulin therapy should be considered when good glycaemic control is not achieved or maintained despite optimal dose and number of OGLDs. It is also suggested as initial therapy in newly diagnosed T2DM, particularly when the level of glycated haemoglobin $(\mathrm{HbA} 1 \mathrm{c})>10 \%$ or fasting plasma glucose (FPG) $>13.0 \mathrm{mmol} / \mathrm{L}$ (Ministry of Health, 2018). Early use of insulin has proven to have greater improvement in $\mathrm{HbA1c}$ and FPG with lower risk or no difference in the occurrence of hypoglycaemia (Westphal et al., 2006; Fonseca et al., 2011). Besides, many complications can be prevented with the early introduction of insulin in the management of suboptimal controlled diabetes (Gerstein et al., 2006; Vinik, 2007; Rubino et al., 2007).

The insulin refusal rate among Type 2 diabetes mellitus (T2DM) patients are high even though some eventually accept the treatment. To enhance patient quality of life and to prevent complications of uncontrolled diabetes, health care providers are responsible to help patients achieve the targeted blood glucose range. However, rejection of insulin therapy is one of the main challenges when treating diabetes patients, particularly those with poor control.

Studies done in several countries suggested that insulin naive patient refusal rate is varied. It ranged from $70.6 \%$ in Singapore, $42.5 \%$ in Bangladesh to nearly $28.2 \%$ in the United States of America region (Wong et al., 2011; Khan et al., 2008; Polonsky et al., 2004). A high refusal rate was observed in a local study which discovered 51\% of participants were reluctant to start insulin therapy (Azmiah et al., 2011).

Patient's acceptance of insulin therapy can be influenced by many factors such as socio-demographic factors, clinical factors or psychological factors. The combination of these factors makes the initiation of insulin therapy even more challenging. Older age was one of the socio-demographic factors that contributed to insulin therapy refusal (Tan et al., 2015; Ghadiri-Anari, et al., 2013; Batais et al., 2016). Gender, particularly female was more likely to refuse insulin therapy (Polonsky et al., 2004; Azmiah et al., 2011; Hassan et al., 2013; Kaur et al., 2018). Other socio-demographic factors that were observed in previous studies included educational backgrounds (Wong et al., 2011; Tan et al., 2015; Batais et al., 2016), employment status (Khalili et al., 2016; Tan et al., 2015), ethnicity (Azmiah et al., 2011; Tan et al., 2015) and marital status (Khalili et al., 2016). Meanwhile, the long duration of having diabetes and poor control of diabetes which was determined by a high level of $\mathrm{HbAlc}$ was known clinical factors for insulin therapy refusal that were already addressed by previous literature (Tan et al., 2015).

Despite the efficacy and benefits of insulin have been proven in many studies, these negative thoughts of patients towards insulin are a huge barrier for them to start insulin therapy. It is important to understand the patient perception of insulin and the reasons for refusal so that better service and counselling for the patient can be provided. Therefore, this study was conducted to determine perception towards insulin among insulin naive T2DM patients. This study was also done to calculate the prevalence of rejecting insulin therapy in the Lipis district. Other than that, this study was done to find out the factors related to insulin therapy refusal.

\section{Materials and methods}

A cross-sectional study was conducted in five primary health clinics in Lipis district, Pahang Malaysia, namely Klinik Kesihatan (KK) Benta, KK Padang Tengku, KK Sungai Koyan, KK Merapoh and Klinik Bergerak Komuniti Lipis for two months from October to November 2017.

A self-administered questionnaire (Appendix 1) was developed by following a similar local study (Azmiah et al., 2011). The first part of the questionnaire included socio-demographic details. The patient's last HbAlc reading was also recorded. The second part of the questionnaire consisted of 20 items (18 negative items and 2 positive items). Scored on a five-point Likert Scale, where strongly disagree $=1$, disagree $=2$, unsure $=3$, agree $=4$, and strongly agree $=5$. For calculation of the total score, the rating of the two positive items were in reverse, with strongly disagree $=5$, disagree $=4$, unsure $=3$, agree 
$=2$, and strongly agree $=1$. The total possible score for the questionnaire was 100. The higher the score indicated a more negative appraisal of insulin therapy. Data are presented as means \pm standard deviation (SD) (Chen et al., 2011).

Epi Info Version 7.2 Stac Calc was used to calculate the sample size for this study - Sample Size and Power with $95 \%$ Confidence level, $74.2 \%$ prevalence of rejecting insulin therapy, $5 \%$ precision and infinite population count (Tan et al., 2015). The minimum sample size required was 353 after a $20 \%$ allowance for non-responders. Respondent's inclusion criteria were those diagnosed with Type II diabetes mellitus (T2DM) with the last HbA1c reading $\geq 7.0 \%$, took two or more OGLDs for at least six months and never use insulin. Patients diagnosed with Type I diabetes mellitus, psychiatric disease or dementia and those with dexterity impairment were excluded from the study. Respondents were conveniently recruited when having follow-up for their T2DM and the consent form, which was adapted from the National Medical Research Register (NMRR), was disseminated to the selected study subjects (Appendix 2).

The prevalence of insulin refusal was calculated using the formula adapted from the Centres for Disease Control and Prevention website (Centres for Disease Control and Prevention. 2012). Data were analysed using Statistical Package for Social Sciences (SPSS) version 21.0. The Chisquare test was used to assess differences in proportion between those who accepted and those who rejected insulin therapy. Simple and multiple logistic regressions were utilised to study the factors related to insulin therapy refusal. A p-value of less than 0.05 was considered to be statistically significant.

The study was approved by the Medical Research Ethics Committee (MREC) Malaysia and registered with the National Medical Research Registry (NMRR ID: NMRR-17-1843-37560)

\section{Results}

A total of 201 patients were approached for the study but only 188 agreed to take part, yielding a response rate of $93.5 \%$. Since a self-administered questionnaire was used as the study instrument for this study, those with low literacy refused to participate. The majority of the respondents were Malay (88.3\%), single/widowed (70.2\%), not working/retired $(73.9 \%)$ with at least secondary education $(50.5 \%)$ and an almost equal number of males and female participated in the study. Their mean age was 57.8 years and the average earning was RM1469.15 \pm 1270.76 . The mean HbA1c reading was $9.17 \% \pm 1.60 \%$.
Table 1: Patient's socio-demographic data and willingness to initiate insulin therapy $(\mathrm{n}=188)$

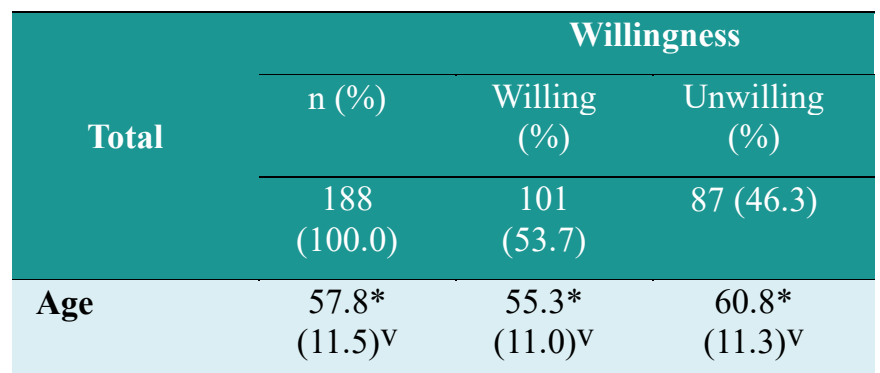

\section{Gender}

$\begin{array}{llll}\text { Male } & 85(45.2) & 27(31.8) & 58(68.2) \\ \text { Female } & 103 & 74(71.8) & 29(28.2) \\ & (54.8) & & \end{array}$

Ethnic

$\begin{array}{llll}\text { Malay } & 166 & 86(51.8) & 80(48.2) \\ \text { Non-Malay } & (88.3) & 15(68.2) & 7(31.8)\end{array}$

Marital

Status

$\begin{array}{lccc}\text { Single/wido } & 132(70.2) & 65(49.2) & 67(50.8) \\ \text { wed } & 56(29.8) & 36(64.3) & 20(35.7) \\ \text { Married } & & & \end{array}$

$\begin{array}{llll}\begin{array}{l}\text { Educational } \\ \text { Level }\end{array} & & & \\ \text { Not } & & & \\ \text { schooling/pri } & 56(29.8) & 46(82.1) & 10(17.9) \\ \text { mary } & & & \\ \begin{array}{l}\text { Secondary } \\ \text { Tertiary }\end{array} & 95(50.5) & 43(45.3) & 52(54.7) \\ & 37(19.7) & 12(32.4) & 25(67.6)\end{array}$

Working

Status

$\begin{array}{lccc}\text { Not working } & 139(73.9) & 84(60.4) & 55(39.6) \\ \text { Working } & 49(26.1) & 17(34.7) & 32(22.7)\end{array}$

$\begin{array}{lccc}\text { Income } & & & \\ \text { RM0 - } & 65(34.6) & 33(50.8) & 32(49.2) \\ \text { RM999 } & 82(43.6) & 44(53.7) & 38(46.3) \\ \text { RM1000 - } & & & \\ \text { RM1999 } & 25(13.3) & 15(60.0) & 10(4.0) \\ \text { RM2000 - } & & & \\ \text { RM2999 } & 16(8.5) & 9(56.2) & 7(43.8) \\ \geq \text { RM3000 } & 9.2^{*}(1.6)^{\mathrm{V}} & 8.8^{*}(1.2)^{\mathrm{V}} & 9.6^{*}(1.6)^{\mathrm{V}} \\ \text { HbA1c } & & \end{array}$

*Mean ${ }^{\mathrm{V}}$ Standard deviation

HbA1c: glycated haemoglobin 
The total possible score for the questionnaire is 100 and the higher the score indicates a more negative appraisal of insulin therapy. Table 2 showed the total score for both respondents' opinions regarding self-efficacy and insulin therapy $(60.5 \pm 8.2)$ indicating the respondents' perceptions were negative towards insulin therapy.

Table 2: Total Score for Self-Efficacy and Opinion Regarding Insulin

\begin{tabular}{lc}
\hline & Mean \pm SD \\
\hline $\begin{array}{l}\text { Opinion regarding } \\
\text { self-efficacy }\end{array}$ & $30.6 \pm 5.7$ \\
\hline $\begin{array}{l}\text { Opinion regarding } \\
\text { insulin }\end{array}$ & $29.9 \pm 4.1$ \\
Total Score: & $60.5 \pm 8.2$ \\
\hline
\end{tabular}

The top three opinions regarding self-efficacy are feeling embarrassed to inject insulin in public (69.1\%), the concern that hypoglycaemia would lead to permanent irreversible damage $(60.1 \%)$ and fear of pain during insulin administration (57.4\%).

Most respondents agreed that insulin might cause frequent hypoglycaemia $(52.7 \%)$. Meanwhile, almost half admitted they were unsure about most of the information regarding insulin such as insulin and needles are more expensive than oral therapy $(42.6 \%)$, whether insulin can be stopped once initiated $(41.0 \%)$.

The prevalence of insulin refusal was presented in the figure below. Four of every ten patients reported unwilling to start insulin therapy $(46.3 \%)$.

Simple logistic regression was conducted to analyse the association between insulin therapy refusal and sociodemographic data, hence deciding the factor(s) that might contribute to insulin refusal. Only factors with a p-value $<$ 0.05 were deemed to be statistically significant. Six factors that fulfilled the criteria, namely age, gender, educational level, employment status, and $\mathrm{HbAlc}$ were further investigated with multiple logistic regressions.

After analysing multiple logistic regressions, only gender, educational level, age, and $\mathrm{HbAlc}$ remained significantly associated with the tendency to accept insulin therapy. While controlling for other factors, women were $20 \%$ more likely to accept insulin therapy, compared to male respondents (adjusted OR 0.20, $95 \%$ CI 0.10-0.40, p $=<0.001)$. Respondents who received tertiary education were $83 \%$ more likely to resist insulin therapy compared to those who received only primary education or with no formal education (adjusted OR 0.17, $95 \%$ CI 0.06-0.50, P $=0.001$ ). Age and $\mathrm{HbA} 1 \mathrm{c}$ were inversely associated with insulin therapy acceptance. For every one-year increase in age, respondents were 1.04 times more likely to reject insulin therapy (adjusted OR 1.04, $95 \%$ CI 1.01-1.08, p = 0.012 ). Similarly, for every $1.0 \%$ increment in $\mathrm{HbA} 1 \mathrm{c}$ level, subjects were 1.33 times more reluctant to initiate insulin therapy (adjusted OR 1.33, $95 \%$ CI 1.07-1.67, p = 0.013).

\section{Discussion}

It is important to address a patient's perception of insulin therapy as many patients were hesitant to use insulin due to their negative beliefs about insulin injection (Hassan et al., 2013). The current study found out that the respondents have a prominent negative belief towards insulin therapy (total score $60.5 \pm 8.2$ ). This finding was comparable to a previous study where their insulin naive T2DM respondents scored $62.9 \pm 7.1$ indicating negative perceptions towards therapy (Ghadiri-Anari et al., 2013). This was understandable as patients tended to worry about the unfamiliar forms of treatment and become a barrier for the patient to start the treatment. By recognizing the patient's hurdle, psychological insulin refusal (PIR) can be overcome. Providing the information and introducing the possible need for insulin early in treatment can improve patient's perceptions towards insulin in general and overcome PIR (Polonsky et al., 2011).

The majority of respondents admitted that they feel embarrassed to inject insulin in public $(69.1 \%)$. It can be inconvenient and embarrassing as insulin needs to be injected at a certain time. This was supported by a previous finding where more than half of the subjects (55.9\%) expressed that injecting insulin in public was embarrassing (Azmiah et al., 2011). The absence of a private area may cause them to inject too early or might entirely omit the dose and eventually resulting in hypo/hyperglycaemia (Chen et al., 2011; Hunt et al., 1997). However, feeling embarrassed to inject insulin in public was the least worrying reason for patients in a previous study done in Kubang Pasu, Kedah (17.5\%) (Tan et al., 2015). 
Table 3: Opinion Regarding Self-Efficacy

\begin{tabular}{llllll} 
No. & & \multicolumn{1}{c}{ Statements } & Mean \pm SD & \multicolumn{3}{c}{ Number (\%) } \\
\cline { 5 - 6 } & & & Disagree & Unsure & Agree \\
\hline $\mathbf{1}$ & Feel embarrassed to inject insulin in public & $3.8 \pm 1.2$ & $34(18.1)$ & $24(12.8)$ & $130(69.1)$ \\
$\mathbf{2}$ & $\begin{array}{l}\text { Concern that hypoglycaemia would lead to } \\
\text { permanent irreversible damage }\end{array}$ & $3.6 \pm 1.0$ & $41(21.8)$ & $34(18.1)$ & $113(60.1)$ \\
$\mathbf{3}$ & Fear of pain during insulin administration & $3.1 \pm 1.1$ & $70(37.3)$ & $10(5.3)$ & $108(57.4)$ \\
$\mathbf{4}$ & Fear of injection & $2.9 \pm 1.3$ & $79(42.0)$ & $9(4.8)$ & $100(53.2)$ \\
$\mathbf{5}$ & $\begin{array}{l}\text { Injecting insulin makes one feel as if he/ she is a } \\
\text { drug addict. }\end{array}$ & $3.1 \pm 1.5$ & $71(37.8)$ & $21(11.2)$ & $96(51.0)$ \\
$\mathbf{6}$ & Lack of confident in injecting insulin & $3.1 \pm 1.2$ & $66(35.1)$ & $45(23.9)$ & $77(41.0)$ \\
$\mathbf{7}$ & $\begin{array}{l}\text { Unable to arrange/ adjust daily activities as } \\
\text { needed in insulin therapy }\end{array}$ & $3.0 \pm 1.3$ & $81(43.1)$ & $36(19.1)$ & $71(37.8)$ \\
$\mathbf{8}$ & Worry about hypoglycaemia & $2.6 \pm 1.4$ & $103(54.8)$ & $20(10.6)$ & $65(34.5)$ \\
$\mathbf{9}$ & $\begin{array}{l}\text { Unable to arrange/ adjust diet as needed in insulin } \\
\text { therapy }\end{array}$ & $2.5 \pm 1.1$ & $109(57.9)$ & $16(8.5)$ & $63(33.5)$ \\
$\mathbf{1 0}$ & Lack of time to inject insulin systematically & $2.4 \pm 1.3$ & $128(68.1)$ & $6(3.2)$ & $54(28.7)$ \\
\hline
\end{tabular}

Table 4: Opinion Regarding Insulin Therapy

\begin{tabular}{|c|c|c|c|c|c|}
\hline \multirow{2}{*}{ No. } & \multirow{2}{*}{ Statements } & \multirow{2}{*}{ Mean $\pm \mathrm{SD}$} & \multicolumn{3}{|c|}{ Number $(\%)$} \\
\hline & & & Disagree & Unsure & Agree \\
\hline 1 & Insulin causes hypoglycaemia frequently. & $3.4 \pm 1.0$ & $37(19.7)$ & $52(27.7)$ & $99(52.7)$ \\
\hline 2 & Insulin contains illegal substances. & $2.9 \pm 1.4$ & $79(42.0)$ & $31(16.5)$ & $78(41.5)$ \\
\hline 3 & Insulin causes a lot of adverse effects in the future. & $2.9 \pm 1.0$ & $75(39.9)$ & $45(23.9)$ & $68(36.2)$ \\
\hline 4 & $\begin{array}{l}\text { Insulin and needles are more expensive than oral } \\
\text { hypoglycaemic agents. }\end{array}$ & $3.2 \pm 0.9$ & $40(37.2)$ & $80(42.6)$ & $68(36.2)$ \\
\hline 5 & Insulin leads to renal failure. & $2.9 \pm 1.5$ & $75(39.9)$ & $51(27.1)$ & $62(33)$ \\
\hline 6 & Insulin therapy leads to dependency. & $2.8 \pm 1.2$ & $72(38.2)$ & $54(28.7)$ & $62(33)$ \\
\hline $7 *$ & $\begin{array}{l}\text { Insulin prevents long-term complications of } \\
\text { uncontrolled diabetes. }\end{array}$ & $3.1 \pm 1.2$ & $66(35.1)$ & $72(38.3)$ & $50(26.6)$ \\
\hline 8 & Insulin therapy cannot be stopped once initiated. & $2.7 \pm 0.9$ & $78(41.5)$ & $77(41.0)$ & $33(17.5)$ \\
\hline 9* & $\begin{array}{l}\text { Insulin is more effective than oral hypoglycaemic } \\
\text { agents. }\end{array}$ & $3.4 \pm 0.9$ & $95(50.5)$ & $62(33.0)$ & $31(16.5)$ \\
\hline 10 & Insulin leads to blindness. & $2.1 \pm 0.9$ & $113(60.1)$ & $65(34.6)$ & $10(5.3)$ \\
\hline
\end{tabular}

*Questions 7 and 9 are the positive questions. 


\section{Prevalence of Insulin Refusal among Insulin Naive Type 2 Diabetes Mellitus ( $\mathbf{n = 1 8 8})$}

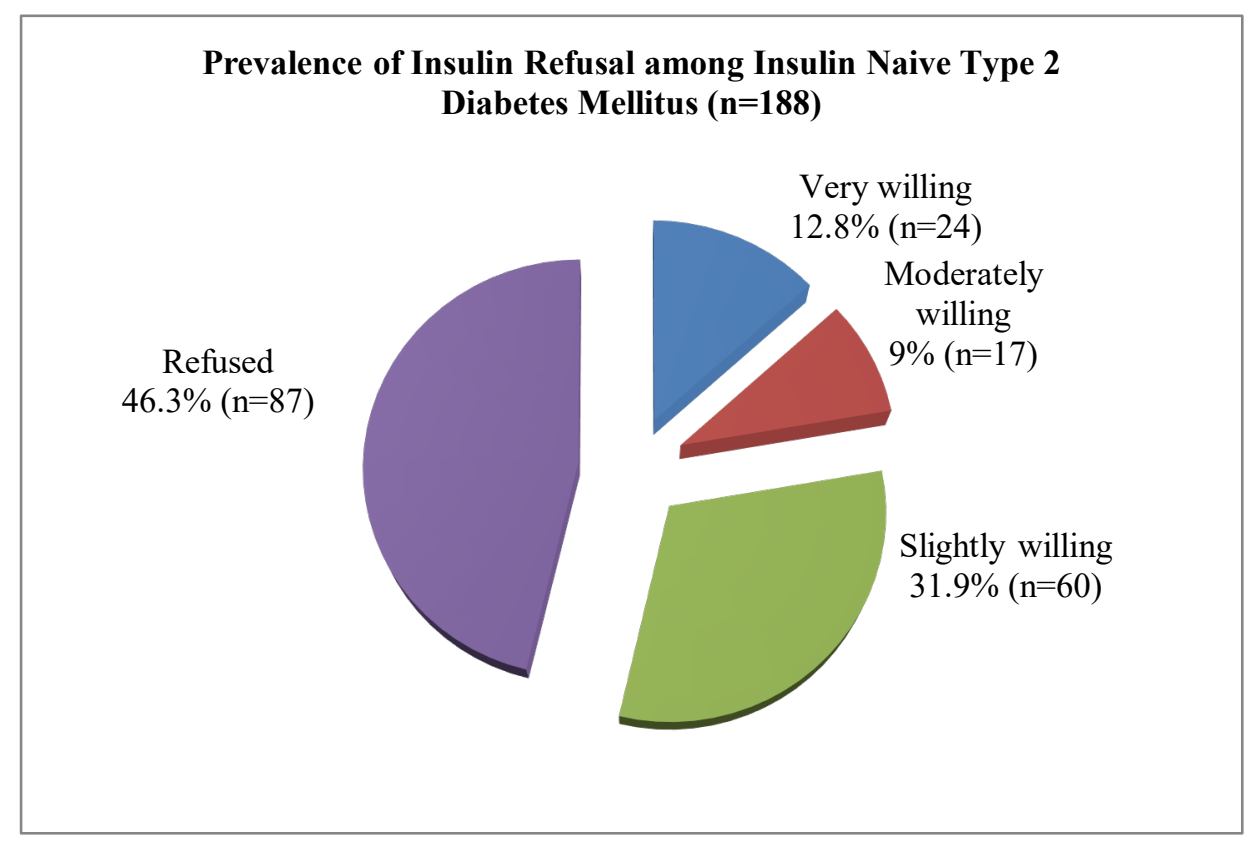

Figure 1: Prevalence of Insulin Refusal among Insulin Naive Type 2 Diabetes Mellitus in Public Patients in Primary Care Clinics PKD Lipis ( $\mathrm{n}=188 ; 58.2 \%$ female; $93.1 \%$ Malay)

Fear of problematic hypoglycaemia was found to be a secondary concern in the current study as most of the patients afraid that hypoglycaemia would lead to permanent irreversible damage $(60.1 \%)$ and agreed that insulin can cause hypoglycaemia frequently $(53.7 \%)$. One of the contributing factors could be because most of the respondents lived alone $(70.2 \%$ of patients were single/widowed) and thus intensified the fear. The DAWN study addressed the fear of hypoglycaemic events as one of the patients' factors that contribute to a poor sense of well-being and thus affecting overall diabetes outcomes (Korytkowski, 2002). The result was comparable to the findings in previous studies where $59.6 \%$ and $47.8 \%$ of patients respectively admitted that they refused insulin due to the fear of problematic hypoglycaemia (Azmiah et al., 2011; Tan et al., 2015).

In the current study, $46.3 \%$ of patients with Type 2 diabetes mellitus who visited public clinics in Lipis denied insulin if the treatment was given to them. This percentage was comparable with previous studies done by Khan et al., (2008) and Azmiah et al., (2011) as $42.5 \%$ and $50.7 \%$ of their respondents respectively unwilling to initiate the treatment. Meanwhile, higher refusal rates were recorded in previous studies done in various countries ranging from 60 to $80 \%$ of refusal rate (Wong et al., 2011; Tan et al., 2015; 1999; Kaur et al., 2018). However, Polonsky et al., (2004) reported the lowest rate with $28.2 \%$ of refusal. Due to geographic factor as the current study was done in a rural setting, health promotion activities to patients are restricted, causing insufficient exposure to health information. Urban populations have a better acceptance of insulin treatment and better access to health information related to disease and treatment (Rubino et al., 2007).

The current study found out that age was inversely associated with insulin therapy acceptance. For every one-year increase in age, respondents were 1.04 more likely to reject insulin therapy $(\mathrm{p}=0.012)$. However, a different finding was observed in previous literature as elderly respondents were more accepting of insulin therapy $(\mathrm{r}=-0.153, \mathrm{p}=<0.05)$ (Rubino et al., 2007). Treating the elderly with diabetes is challenging as they are at an increased risk rate of concomitant illnesses such as hypertension, renal impairment, and heart diseases. Polypharmacy is also one of the concerns as patients will be more concerned regarding possible drug-drug interaction and the idea of adding insulin into the treatment will cause more worries and cause them to refuse the therapy (Ministry of Health, 2015). However, several previous studies found no significant difference between age groups and willingness to start insulin therapy (Tan et al., 2015; Ghadiri-Anari, et al., 2013; Batais et al., 2016). 
Some previous studies discovered that male patients were more likely to accept the insulin initiation which male patients were said to be naturally less fearful of injection (Polonsky et al., 2004; Hassan et al., 2013; Kaur et al., 2018). A local study was done by Azmiah et al., (2011) also found out that female patients were 2.7 times more likely to refuse insulin initiation. However, in the current study female respondents were $20 \%$ more expected to accept insulin therapy, compared to males $(\mathrm{p}=<0.001)$.

As found in previous studies, patients with higher educational backgrounds were less likely to refuse insulin initiation. Wong et al., (2011) revealed that patients with tertiary level of education were more willing to start insulin therapy. Same finding was observed in local study in which patient with at least a secondary education was $55.0 \%$ less likely to refuse insulin as patients with higher education are expected to be more receptive towards knowledge on disease and insulin therapy (Tan et al., 2015). However, the current study found out that respondents who received tertiary education were $83.0 \%$ more likely to resist insulin therapy $(\mathrm{p}=0.001)$ and supported by a previous study done in Saudi Arabia as those with tertiary education were $48 \%$ unwilling to initiate insulin therapy $(\mathrm{p}=0.023)$ (Batais et al., 2016).

The recent study reported $\mathrm{HbA} 1 \mathrm{c}$ level was related to the refusal as for every $1.0 \%$ increment in $\mathrm{HbAlc}$ level subjects were 1.33 times more reluctant to initiate insulin therapy $(p=0.013)$. Similar findings were recorded in previous studies where a significant relationship was found between patient's willingness for insulin initiation with $\mathrm{HbAlc}$ level (Azmiah et al., 2011; Tan et al., 2015). A different finding was observed by Wong et al., (2011) in which those who were reluctant to start the treatment were among the lower mean $\mathrm{HbAlc}$ group. Compared to the other studies, patients with $\mathrm{HbA} 1 \mathrm{c}>7 \%$ were recruited in the recent study. According to previous literature patient with higher $\mathrm{HbAlc}$ tends to refuse insulin therapy more than those with lower HbAlc as a higher dose of insulin initiation is needed and thus higher concern for hypoglycaemia (Hayward, 1997; Abraira et al., 1995).

However, some limitations should be noted. The current study has a limited number of respondents as those with the last $\mathrm{HbAlc}$ reading $<7.0 \%$ were excluded from the study. The minimum sample size required was 353 after a $20 \%$ allowance for nonresponders. However, only 188 respondents agreed to participate in the study, causing difficulty to identify significant relationships from the data. The questionnaire given was self-administered. Thus, those with low literacy tended to avoid participating in the study.

\section{Conclusion}

Overall, insulin naive T2DM patients in primary care clinics in the Lipis district demonstrated a high level of negative perception towards insulin therapy (mean score $=60.5 \pm 8.2$ ). Almost half of them $(46.3 \%)$ were reluctant to start insulin therapy when being suggested by their doctors. Most patients still have negative opinions regarding insulin and self-efficacy which resulted in a great influence on their willingness to start the therapy. In the future, factors that might be associated with insulin refusal should be addressed possibly in every patient so that the refusal rate can be reduced.

\section{Acknowledgements}

\section{Conflict of Interest}

The authors whose names are listed above certify that they have NO affiliations with or involvement in any organization or entity with any financial interest or non-financial interest in the subject matter or materials discussed in the manuscripts.

\section{References}

Abraira, C., Colwell, J. A., Nuttall, F. Q., Sawin, C. T., Nagel, N. J., Comstock, J. P., ... \& VA CSDM Group. (1995). Veterans Affairs Cooperative Study on glycemic control and complications in Type II diabetes (VA CSDM): results of the feasibility trial. Diabetes care, 18(8), 1113-1123. https://doi.org/10.2337/diacare.18.8.1113

Azmiah, N. Z., Zulkarnain, A. K., \& Tahir, A. (2011). Psychological insulin resistance (PIR) among Type 2 diabetes patients at public health clinics in federal territory of Malaysia. International Medical Journal Malaysia, 10(2), 7-12. doi:10.31436/imjm.v10i2.675

Batais, M. A., \& Schantter, P. (2016). Prevalence of unwillingness to use insulin therapy and its associated attitudes amongst patients with Type 2 diabetes in Saudi Arabia. Primary care diabetes, 10(6), 415-424. https://doi.org/10.1016/j.pcd.2016.05.007

Centers for Disease Control and Prevention. (2012). Principles of epidemiology in public health practice, Third Edition - An introduction to applied epidemiology and biostatistic. Retrieved from: https://www.cdc.gov/csels/dsepd/ss1978/lesson3/s 
ection2.html

Chen, C. C., Chang, M. P., Hsieh, M. H., Huang, C. Y., Liao, L. N., \& Li, T. C. (2011). Evaluation of perception of insulin therapy among Chinese patients with Type 2 diabetes mellitus. Diabetes \& metabolism, 37(5), 389-394.

https://doi.org/10.1016/j.diabet.2010.12.008

Fonseca, V., Gill, J., Zhou, R., \& Leahy, J. (2011). An analysis of early insulin glargine added to metformin with or without sulfonylurea: impact on glycaemic control and hypoglycaemia. Diabetes, Obesity and Metabolism, 13(9), 814-822. https://doi.org/10.1111/j.1463-1326.2011.01412.x

Gerstein, H. C., Yale, J. F., Harris, S. B., Issa, M., Stewart, J. A., \& Dempsey, E. (2006). A randomized trial of adding insulin glargine vs. avoidance of insulin in people with Type 2 diabetes on either no oral glucose-lowering agents or submaximal doses of metformin and/or sulphonylureas. The Canadian INSIGHT (Implementing New Strategies with Insulin Glargine for Hyperglycaemia Treatment) Study. Diabetic Medicine, 23(7), 736-742. https://doi.org/10.1111/j.1464-5491.2006.01881.x

Ghadiri-Anari, A., Fazaelipoor, Z., \& Mohammadi, S. M. (2013). Insulin refusal in Iranian patients with poorly controlled Type 2 diabetes mellitus. Acta Medica Iranica, 567-571.

Hassan, H. A., Tohid, H., Amin, R. M., Bidin, M. B. L., Muthupalaniappen, L., \& Omar, K. (2013). Factors influencing insulin acceptance among Type 2 diabetes mellitus patients in a primary care clinic: a qualitative exploration. BMC family practice, 14(1), 164. doi:10.1186/1471-2296-14164

Hayward, R. A., Manning, W. G., Kaplan, S. H., Wagner, E. H., \& Greenfield, S. (1997). Starting insulin therapy in patients with Type 2 diabetes: effectiveness, complications, and resource utilization. Jama, 278(20), 1663-1669. doi: 10.1001/jama.1997.035502000392029

Hunt, L. M., Valenzuela, M. A., \& Pugh, J. A. (1997). NIDDM patients' fears and hopes about insulin therapy: the basis of patient reluctance. Diabetes care, 20(3), 292-298. https://doi.org/10.2337/diacare.20.3.292

Kaur T, Dubey A, \& Agrawal B. (2018). Why are Type 2 diabetics refusing insulin? A hospital based study to find the factors influencing the patient's readiness for insulin. International Journal of Scientific Research. Apr: 4:7. doi: 10.36106/ijsr
Khalili M, Sabouhi F, Abazari P, Aminorroaya A (2016). Comparing the quality of life in insulin recipient and refusal patients with Type 2 diabetes. Iranian journal of nursing and midwifery research. 21(4):351. doi: 10.4103/1735-9066.185571

Khan, H., Lasker, S. S., \& Chowdhury, T. A. (2008). Prevalence and reasons for insulin refusal in Bangladeshi patients with poorly controlled Type 2 diabetes in East London. Diabetic Medicine, 25(9), 1108-1111. https://doi.org/10.1111/j.1464-5491.2008.02538.x

Korytkowski, M. (2002). When oral agents fail: practical barriers to starting insulin. International Journal of Obesity, 26(3), S18-S24. https://doi.org/10.1038/sj.ijo.0802173

Ministry of Health. (2012). Non-Communicable Disease Section. National Diabetes Registry Report. Retrieved from: http://www.moh.gov.my/moh/resources/Penerbita n/Rujukan/NCD/Diabetes/National_Diabetes_Reg istry_Report_Vol_1_2009_2012.pdf_

Ministry of Health. (2015). National Health \& Morbidity Survey 2015. Non-Communicable Diseases, Risk Factors \& Other Health Problems. Retrieved from:

http://iku.moh.gov.my/images/IKU/Document/RE PORT/nhmsreport2015vol2.pdf

Ministry of Health. (2020). Clinical Practice Guidelines. Management of Type 2 Diabetes Mellitus $\left(6^{\text {th }}\right.$ Edition): Ministry of Health.

Polonsky, W. H., Hajos, T. R., Dain, M. P., \& Snoek, F. J. (2011). Are patients with Type 2 diabetes reluctant to start insulin therapy? An examination of the scope and underpinnings of psychological insulin resistance in a large, international population. Current medical research and opinion, 27(6), 1169-1174. https://doi.org/10.1185/03007995.2011.573623

Polonsky, W. H., \& Jackson, R. A. (2004). What's so tough about taking insulin? Addressing the problem of psychological insulin resistance in Type 2 diabetes. Clinical diabetes, 22(3), 147-150. https://doi.org/10.2337/diaclin.22.3.147

Rubino, A., McQuay, L. J., Gough, S. C., Kvasz, M., \& Tennis, P. (2007). Delayed initiation of subcutaneous insulin therapy after failure of oral glucose-lowering agents in patients with Type 2 diabetes: a population-based analysis in the UK. Diabetic Medicine, 24(12), 1412-1418. https://doi.org/10.1111/j.1464-5491.2007.02279.x

Tan, W. L., Asahar, S. F., \& Harun, N. L. (2015). Insulin 
therapy refusal among Type II diabetes mellitus patients in Kubang Pasu district, Kedah,

Malaysia. Singapore medical journal, 56(4), 224227. doi: $10.11622 /$ smedj.2014170

Vinik, A. (2007). Advancing therapy in Type 2 diabetes mellitus with early, comprehensive progression from oral agents to insulin therapy. Clinical therapeutics, 29(6), 1236-1253.

https://doi.org/10.1016/j.clinthera.2007.07.005

Westphal, S. A., \& Palumbo, P. J. (2006). A case for introducing insulin early in the treatment of Type 2 diabetes mellitus. Insulin, 1(2), 65-69.

https://doi.org/10.1016/S1557-0843(06)80012-6

Wong, S., Lee, J., Ko, Y., Chong, M. F., Lam, C. K., \& Tang, W. E. (2011). Perceptions of insulin therapy amongst Asian patients with diabetes in Singapore. Diabetic medicine, 28(2), 206-211. https://doi.org/10.1111/j.1464-5491.2010.03195.x 